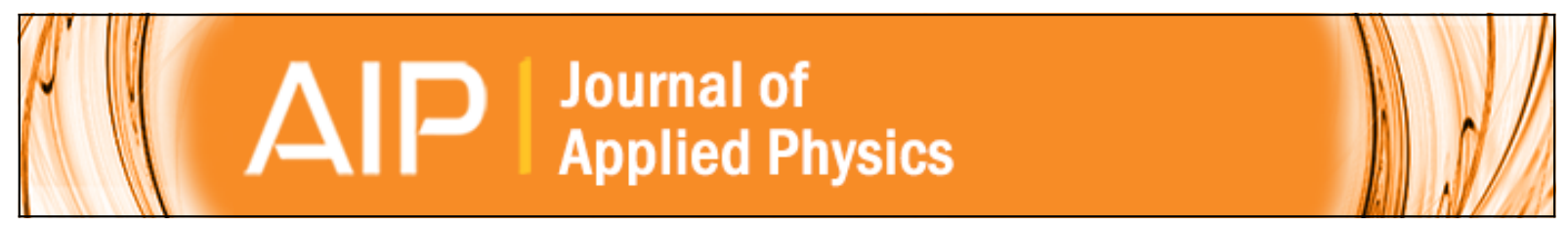

\title{
Tungstate fluorophosphate glasses as optical limiters
}

Gaël Poirier, Cid B. de Araújo, Younes Messaddeq, Sidney J. L. Ribeiro, and Marcel Poulain

Citation: Journal of Applied Physics 91, 10221 (2002); doi: 10.1063/1.1481770

View online: http://dx.doi.org/10.1063/1.1481770

View Table of Contents: http://scitation.aip.org/content/aip/journal/jap/91/12?ver=pdfcov

Published by the AIP Publishing

\section{AlP}

\section{Create a profile. \\ Sign up today!}




\section{Tungstate fluorophosphate glasses as optical limiters}

Gaël Poirier

Instituto de Química, UNESP, PC 355, CEP 14801-970, Araraquara SP, Brazil and Laboratoire des Matériaux Photoniques, Bât 10B, Campus de Beaulieu, Université de Rennes I, Rennes, France

Cid B. de Araújo ${ }^{\mathrm{a})}$

Departamento de Física, Universidade Federal de Pernambuco, 50670-901 Recife, PE, Brazil

Younes Messaddeq and Sidney J. L. Ribeiro

Instituto de Química, UNESP, PC 355, CEP 14801-970, Araraquara SP, Brazil

Marcel Poulain

Laboratoire des Matériaux Photoniques, Bât 10B, Campus de Beaulieu, Université de Rennes I, Rennes, France

(Received 28 January 2002; accepted for publication 8 April 2002)

Nonlinear absorption measurements were performed on fluorophosphate glasses with high concentrations of tungsten oxide. Large two-photon absorption coefficients, $\alpha_{2}$, were determined at $660 \mathrm{~nm}$ using nanosecond laser pulses. It was observed that $\alpha_{2}$ increases for increasing tungsten oxide concentrations and, hence, the optical limiting performance of this glass composition can be controlled. () 2002 American Institute of Physics. [DOI: 10.1063/1.1481770]

Optical limiting (OL) materials have been intensively studied due to their potential to protect sensitive optical components and human eyes from damage as well as to smooth optical transients. ${ }^{1,2}$ Various phenomena are exploited for OL, such as nonlinear absorption and nonlinear refraction, ${ }^{1-4}$ nonlinear light scattering, ${ }^{5}$ and polarization changes, ${ }^{6}$ among others.

Organic materials are efficient optical limiters but their maximum efficiency occurs usually for long pulse durations. Other drawbacks of these materials are their poor stability and large linear absorption. On the other hand, inorganic two-photon absorbers are stable, transparent under low intensity, and present instantaneous response. For practical applications, glasses with large two-photon absorption (TPA) coefficients are important candidates for OL because their fabrication processes are more convenient than for crystals of good optical quality with appropriate size.

In this work we evaluate the nonlinear absorption behavior of fluorophosphate glasses with high tungsten concentrations for OL. It is already known that phosphate glass is not a good nonlinear absorber. ${ }^{7}$ However, the choice of this material was due to the knowledge that transition metal ions when surrounded by oxygen atoms may generate a high optical nonlinearity. ${ }^{8,9}$ In fact, our glasses, prepared in the $\mathrm{NaPO}_{3}-\mathrm{BaF}_{2}-\mathrm{WO}_{3}$ system, have shown an efficient OL behavior under $660 \mathrm{~nm}$ excitation with nanosecond laser pulses. The TPA coefficient was determined for samples with different concentrations of $\mathrm{WO}_{3}$ and the results are comparable to the values reported for semiconductor crystals ${ }^{10}$ indicating a large potential of the glass composition for devices.

\footnotetext{
a) Author to whom correspondence should be addressed; electronic mail:
} cid@df.ufpe.br
The glass preparation was already reported ${ }^{11}$ and the composition of the samples studied are presented in Tables I and II of good optical quality with dimensions of about 1 $\mathrm{cm} \times 1 \mathrm{~cm} \times 0.2 \mathrm{~cm}$ were obtained.

The OL measurements were performed using a dye laser $(660 \mathrm{~nm}, 8 \mathrm{~ns}, 5 \mathrm{~Hz})$ pumped by the second harmonic of a $Q$-switched Nd:yttrium-aluminum-garnet laser. The dye laser beam was split in 2: one beam was used to monitor the incident intensity and the other beam was focused onto the sample using a $10 \mathrm{~cm}$ focal lens. The intensities of the incident and the transmitted pulses were simultaneously measured using two photodetectors connected to a fast oscilloscope. The sample position was varied along the beam direction so that the incident intensity could be varied without changing the pulse energy.

The absorption spectra of the samples were measured at room temperature in the $300-1000 \mathrm{~nm}$ range and are shown in Fig. 1. Note that the vitreous samples are transparent in the near infrared and visible and the absorption band gap occurs at $\approx 400 \mathrm{~nm}$. The features at $\approx 800 \mathrm{~nm}$ are due to the exchange of lamps in the spectrophotometer.

The behavior of the samples under laser excitation is illustrated in Fig. 2. Note that the sample NBW30 does not show OL whereas samples NBW40 and NBW50 present a pronounced optical attenuation as the input intensity increases. We assumed that the nonlinear absorption is due to a TPA process because the energy of two incident photons at

TABLE I. Chemical compositions and color of the samples studied in this work.

\begin{tabular}{lcccl}
\hline \hline & $\% \mathrm{~mol} \mathrm{NaPO}_{3}$ & $\% \mathrm{~mol} \mathrm{BaF}_{2}$ & $\% \mathrm{~mol} \mathrm{WO}_{3}$ & Sample color \\
\hline NBW30 & 56 & 14 & 30 & Transparent \\
NBW40 & 48 & 12 & 40 & Yellow \\
NBW50 & 40 & 10 & 50 & Yellow-gray \\
\hline \hline
\end{tabular}


TABLE II. Parameters used to fit the data of Figs. 2 and 3 using Eq. (2). $n_{1}$ is the refractive index measured at $633 \mathrm{~nm}, R$ is the reflectance of each sample face, $L$ is the sample thickness, and $\alpha_{1}$ and $\alpha_{2}$ are the one- and two-photon absorption coefficients.

\begin{tabular}{|c|c|c|c|c|c|}
\hline Sample & $\begin{array}{c}n_{1} \\
\text { (at } 633 \mathrm{~nm} \text { ) }\end{array}$ & $\begin{array}{c}R \\
(\text { at } 633 \mathrm{~nm})\end{array}$ & $L(\mathrm{~cm})$ & $\begin{array}{c}\alpha_{1} \\
\left(\mathrm{~cm}^{-1}\right) \\
(\text { at } 660 \mathrm{~nm})\end{array}$ & $\begin{array}{c}\alpha_{2} \\
(\mathrm{~cm} / \mathrm{G} \mathrm{W}) \\
(\text { at } 660 \mathrm{~nm})\end{array}$ \\
\hline NBW30 & 1.63 & 0.057 & 0.18 & 0.29 & $\cdots$ \\
\hline NBW40 & 1.69 & 0.065 & 0.18 & 0.32 & 5.6 \\
\hline NBW50 & 1.75 & 0.074 & 0.18 & 0.43 & 11 \\
\hline
\end{tabular}

$660 \mathrm{~nm}\left(30300 \mathrm{~cm}^{-1}\right)$ is larger than the band gap energy of the samples which vary from 25600 to $27700 \mathrm{~cm}^{-1}$, depending on the compositions. The transmittance of the samples, $T$, was calculated as the ratio among the output (transmitted) intensity and the input intensity. The results plotted in Fig. 3 show a nonlinear decrease of $T$ as the laser intensity increases. The role played by the tungstate oxide is clear from Figs. 2 and 3.

The light attenuation through the nonlinear sample is described by

$$
\frac{d I}{d z}=-\left(\alpha_{1} I+\alpha_{2} I^{2}\right),
$$

where $I$ is the light intensity along the propagation direction $z, \alpha_{1}$ is the linear absorption coefficient, and $\alpha_{2}$ is the TPA coefficient.

The solution of Eq. (1), integrated from $z=0$ to $z=L$, is given by

$$
I_{L}=\frac{I_{0}(1-R)^{2} \exp \left(-\alpha_{1} L\right)}{1+\left(\alpha_{2} / \alpha_{1}\right) I_{0}(1-R)\left[1-\exp \left(-\alpha_{1} L\right)\right]},
$$

where $R$ is the reflectance of each sample face and $L$ is the sample thickness. The nonlinear transmittance is given by $T=I_{L} / I_{0}$.

The value of $\alpha_{2}$ is obtained by fitting Eq. (2) to the experimental data presented in Figs. 2 or 3, using a nonlinear curve fitting procedure. The results obtained are summarized in Table II. We observe that the values of $\alpha_{2}$ for the samples

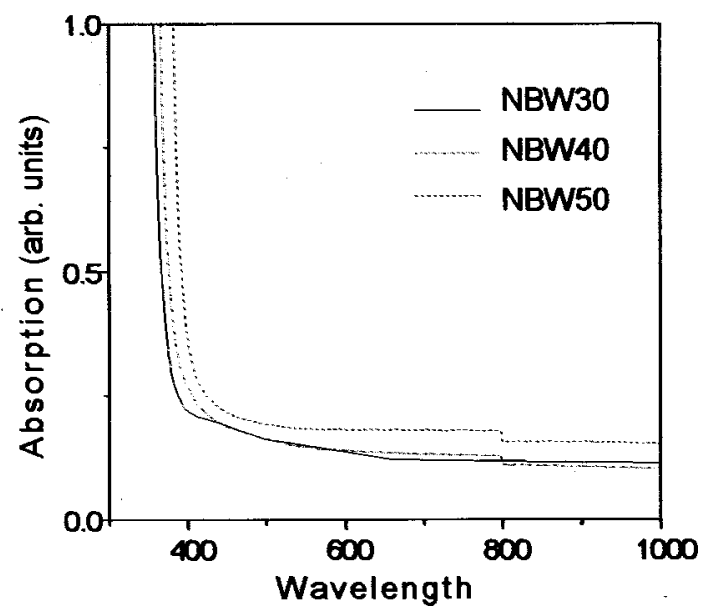

FIG. 1. Linear absorption spectra of the studied samples. The thicknesses of the samples are given in Table II.

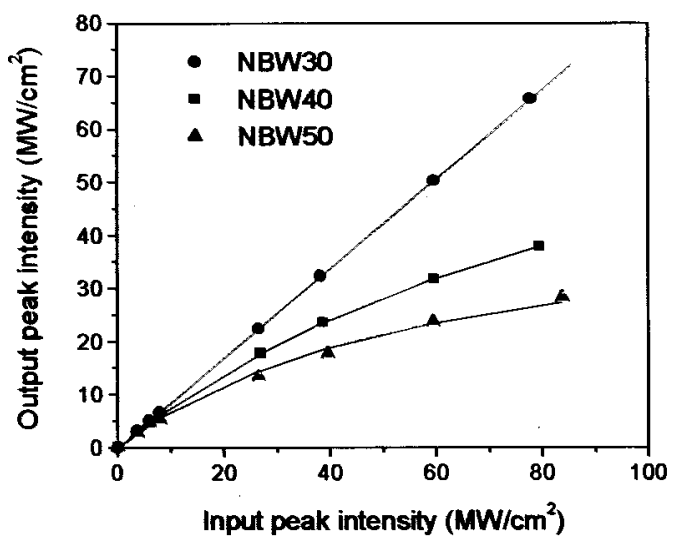

FIG. 2. Optical limiting behavior of the tungstate fluorophosphate glasses for excitation at $660 \mathrm{~nm}$.

NBW40 and NBW50 are larger by more than one order of magnitude than values reported for other phosphate glasses. ${ }^{7}$ Moreover, we note that the present values of $\alpha_{2}$ are comparable with the TPA coefficients reported for chalcogenide glasses $^{12}$ and glass ceramics. ${ }^{13,14}$

The increase of $\alpha_{2}$ for the samples with larger concentration of tungstate oxide should be correlated to possible structural changes in the glass. It was already shown by Raman spectroscopy ${ }^{11}$ that the tungsten oxide units appears as $\mathrm{WO}_{4}$ tetrahedral units for concentrations smaller than $30 \%$ but appears as a mixture of $\mathrm{WO}_{4}$ tetrahedral and $\mathrm{WO}_{6}$ octahedral units for concentrations larger than $40 \%$, with an increase of the $\mathrm{WO}_{6}$ proportion by increasing the tungsten oxide concentration. We recall that clusters of transition metal, including tungsten, enhance the nonlinear properties of glasses. ${ }^{15}$ Possibly, in the present case, the enhancement of $\alpha_{2}$ results mainly from the hyperpolarizabilities associated to $\mathrm{W}-\mathrm{O}$ bonds in clusters of $\mathrm{WO}_{6}$ octahedral units. Further structural investigations by extended $\mathrm{x}$-ray absorption fine structure (EXAFS) and x-ray absorption near edge structure (XANES) studies on the tungsten atom are in progress in order to have more precise details of the microscopic structure of the glasses.

In summary, TPA coefficients were determined for tungstate fluorophosphate glasses. It was demonstrated that the nonlinear absorption is strongly dependent on the tungsten

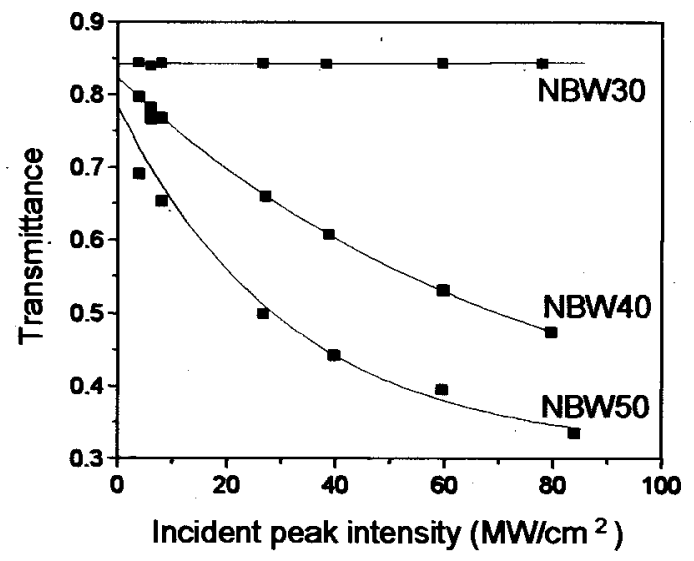

FIG. 3. Nonlinear transmittance response vs the incident peak intensity. 
oxide concentration being enhanced when the fraction of $\mathrm{WO}_{6}$ octahedral units in the glass increases. The behavior observed for samples with a high tungsten oxide concentration indicates the large potential of this glass for OL.

The authors acknowledge the financial support from Programa Nacional de Núcleos de Excelência-PRONEX/MCT (Brazil) and Conseil Régional de Bretagne (France).

${ }^{1}$ Mater. Res. Soc. Symp. Proc. 597, 2000 (complete issue).

${ }^{2}$ J. S. Shirk, Opt. Photonics News 11, 19 (2000).

${ }^{3}$ L. W. Tutt and T. F. Boggess, Prog. Quantum Electron. 17, 299 (1993).

${ }^{4}$ W. Sun, C. C. Byeon, C. M. Lawson, G. M. Gray, and D. Wang, Appl. Phys. Lett. 77, 1759 (2000).

${ }^{5}$ X. Sun, R. Q. Yu, G. Q. Xu, T. S. A. Hor, and W. Ji, Appl. Phys. Lett. 73, 3632 (1998).
${ }^{6}$ F. E. Hernandez, S. Yang, D. Hagan, and E. W. Van Stryland, Mol. Cryst. Liq. Cryst. 358, 301 (2001)

${ }^{7}$ T. Hashimoto, H. Uchida, I. Takagi, H. Nasu, and K. Kamiya, J. NonCryst. Solids 253, 30 (1999).

${ }^{8}$ S. H. Kim and T. Yoko, J. Am. Ceram. Soc. 78, 1061 (1995).

${ }^{9}$ H. Nasu, T. Ito, H. Hase, J. Matsuoka, and K. Kamiya, J. Non-Cryst. Solids 204, 78 (1996).

${ }^{10}$ See, for instance, D. C. Hutchings and E. W. Van Stryland, J. Opt. Soc. Am. B 9, 2065 (1992), and references therein.

${ }^{11}$ G. Poirier, Y. Messaddeq, S. J. L. Ribeiro, and M. Poulain, J. Non-Cryst. Solids (in press).

${ }^{12}$ C. Quémard, F. Smektala, V. Coudere, A. Barthélémy, and J. Lucas, J. Phys. Chem. Solids 62, 1435 (2001).

${ }^{13}$ G. S. Maciel, N. Rakov, C. B. de Araujo, A. A. Lipovskii, and D. K. Tagantsev, Appl. Phys. Lett. 79, 584 (2001).

${ }^{14}$ G. S. Maciel, C. B. de Araujo, A. A. Lipovskii, and D. K. Tagantsev, Opt. Commun. 203, 441 (2002).

${ }^{15}$ P. Chakraborty, J. Mater. Sci. 33, 2235 (1998). 